\title{
Degradation of Cyanides in Wastewater from Gold Mining: A Review of Literature
}

\author{
${ }^{1}$ Carlos Vidal-Tovar, ${ }^{1}$ Carlos Cadavid-Osorio, ${ }^{2}$ Rafael Correa-Turizo, \\ ${ }^{2,3}$ Carlos Severiche-Sierra and ${ }^{4}$ Wilman Cabrera-Lafaurie \\ ${ }^{1}$ Universidad Popular del Cesar, Grupo de Investigacion, Creando Ciencia (CRECI), \\ Valledupar, Cesar, Colombia \\ ${ }^{2}$ Universidad de Cartagena, Grupo de Investigacion Medio Ambiente, Alimentos y Salud-MAAS, \\ Cartagena de Indias, Bolivar, Colombia \\ ${ }^{3}$ Corporacion Universitaria Minuto de Dios (UNIMINUTO), Grupo de Investigacion DESOGUE, \\ Barranquilla, Atlantico, Colombia \\ ${ }^{4}$ Corporacion Universidad de la Costa (CUC), Grupo de Investigacion GICNEX, \\ Barranquilla, Atlantico, Colombia
}

\begin{abstract}
Among the persistent chemical compounds in the residual discharges are the highly toxic cyanides used in the industrial sector and in particular the mining industry for the extraction of gold, frequently appearing in low concentrations in the water, deteriorating its quality. Being of vital importance the treatment of the cyanide effluent, to reduce the concentration of cyanide before its final discharge, thus producing less toxic effluents, to achieve this several studies have been carried out and developed methods for its treatment, chemical, physical and biological An alternative to improve the quality of wastewater is the heterogeneous photocatalysis mediated by different semiconductors such as $\mathrm{TiO}_{2}$, considering this a simple technology and economical in relation to bioremediation treatments, effective and innovative in our environment for aqueous effluents.
\end{abstract}

$\underline{\text { Key words: Cyanized waters, environmental pollution, gold mining, liquid spills, quality, toxic effluents }}$

\section{INTRODUCTION}

The chemical industry and other industries related to it generate residual waste in the form of water streams which in many cases contain organic matter in concentrations too low without significant environmental impact, or high becoming a source of pollution which represents an important burden for the conservation of the environment (Garcia-Ochoa and Santos 2001; Yeddou et al., 2011, Olivero-Verbel et al., 2011, Barrios et al., 2017).

In the last three decades the world environmental legislation has focused on demanding the protection of bodies of water, because the shortage of water and the dramatic increase of diseases and dysfunctions of the nervous system in animals and in man have given voice alert to take measures on the need for the preservation of this natural resource (Moussavi et al., 2018; Anonymous, 1984).

Among the organic compounds and groups of persistent pollutants in the residual discharges are cyanides that are highly toxic (Chiang et al., 2003;
Guadalima and Monteros, 2018) are used in the industrial sector to produce study, textiles and plastics. They are also, present in the chemicals that are used to reveal photographs. Cyanide salts are used in metallurgy for galvanization, metal cleaning and recovery of gold from the rest of the material removed and cyanide gas is used to exterminate pests and insects in ships and buildings (Sarla et al., 2004; Pirmoradi et al., 2017).

The cyanide present in streams of acidulated water form $\mathrm{HCN}$ that is highly toxic if the water has a basic $\mathrm{pH}$ is maintained as cyanide, being necessary to reduce the levels of cyanide in the wastewater before being discharged to the natural channels, for the problems social and public health issues (Irfan et al., 2017; Dash et al., 2009a, b).

Studies carried out by Final Evaluation Report of the Regional Corporation of Southern Bolivar, 2003 show the presence of cyanides that are of environmental and toxicological interest at low concentrations which can cause effects on plant, animal and human organisms (Garcia-Ochoa and Santos 2001; Pala et al., 2015). In

Corresponding Author: Carlos Vidal-Tovar, Universidad Popular del Cesar, Grupo de Investigacion, Creando Ciencia (CRECI), Valledupar, Cesar, Colombia 
human health, it prevents the cells of the body from receiving oxygen causing tissue hypoxia and cyanosis, whose symptoms are: rapid, deep breathing, convulsions, loss of consciousness and asphyxia through inhalation ingestion or absorption through the skin (Kuyucak and Akcil, 2013).

Most of the studies quantify the cyanides present in the waters, others post absorbent that could recover or trap the cyanide but they would be transferring the problem of a pollutant in an aqueous effluent to a solid waste contaminated, not giving a true solution. In Colombia, the discharge regulations in decree 1594 of 1984 under Article 38, establishes that the concentration of cyanide admissible for human and domestic consumption is $0.2 \mathrm{mg} / \mathrm{L}$ in accordance with Resolution 1074 of October 28, 1997 issued by the DAMA, the allowed values of cyanide to be conducted to a body of water are $1.0 \mathrm{mg} / \mathrm{L}$ and the EPA established a maximum contamination level of $0.2 \mathrm{mg} / \mathrm{L}$ in drinking water.

Considering the treatment or purification of wastewater, the development of new technologies has been promoted such as heterogeneous photocatalysis mediated by different semiconductors, one of which is $\mathrm{TiO}_{2}$, considering it a simple, economical technology in relation to bioremediation treatments, efficient and innovative in our means for aqueous effluents (Jaramillo et al., 2002; Dwivedi et al., 2016).

One of the advantages of this technology may lie in profitability and the possibility of using solar radiation as an energy source. Currently there are solar collectors for the degradation of organic compounds (Plataforma Solar de Almeria), using $\mathrm{TiO}_{2}$ as a photocatalyst in which satisfactory results have been found (Malato et al., 2002; Vidal et al., 1999; Ray, 1999). Heterogeneous photocatalysis, unlike most physicochemical processes is not selective and can be used to treat complex mixtures of contaminants (Jaramillo et al., 2002; Mesa, 1998; Gebresemati et al., 2017).

\section{MATERIALS AND METHODS}

Generalities of cyanide: It is a highly dangerous and poisonous chemical that contains carbon and nitrogen is usually found combined with other chemicals forming compounds. For example, simple compounds of cyanide are hydrogen cyanide, sodium cyanide and potassium cyanide. Due to its properties, cyanide is used in the manufacture of metal parts and in numerous organic products such as plastics, synthetic fabrics, fertilizers, herbicides, dyes and pharmaceuticals. It is also, used in
Table 1: Phy sicochemical properties of cyanide compounds

\begin{tabular}{lll}
\hline Properties & Sodium cyanide & Hydrogen cyanide \\
\hline $\begin{array}{l}\text { Fusion point }\left({ }^{\circ} \mathrm{C}\right) \\
\text { Boiling point }\left({ }^{\circ} \mathrm{C}\right)\end{array}$ & 563.7 & -13.4 \\
Solubility $(\mathrm{g} / 100 \mathrm{~g}$ of & 1496 & 25.70 \\
$\left.\mathrm{H}_{2} \mathrm{O}\right)$ at $10^{\circ} \mathrm{C}$ & 48 & Miscible \\
$($ Organic solvents $)$ & $\begin{array}{l}\text { Ethanol, } \\
\text { formaldehy de }\end{array}$ & Ethanol, ether \\
& It has no data & $5.1 \times 10^{-2}$ \\
Ka & $0.76\left(\right.$ at $\left.800^{\circ} \mathrm{C}\right)$ & $630\left(\right.$ at $\left.20^{\circ} \mathrm{C}\right)$ \\
Density $\left(\mathrm{g} / \mathrm{cm}^{3}\right)$ & 1.60 & $0.6884\left(\mathrm{Liquid}\right.$ at $\left.20^{\circ} \mathrm{C}\right)$ \\
Molecular mass & 49.01 & 27.03 \\
Color & White & Transparent \\
Physical state & solid & Gas or liquid \\
Odor & Odorless & Almond \\
\hline
\end{tabular}

Own elaboration

the chemical industry due to its composition and the ease with which it reacts with other compounds (Acheampong and Lens, 2014).

The signs and symptoms of the CNS (Central Nervous System) are typical and progressive: hypoxia includes headaches, agitation confusion, seizures, lethargy, coma and death. Initially there is a tachypnea of central origin followed by bradypnea, hypotension and bradycardia. Cardiogenic and non-cardiogenic pulmonary edema and gastrointestinal disorders (not frequent) may occur: abdominal pain, nausea and vomiting. The time of onset of symptoms is rapid (10-15 min) with gaseous and inorganic forms, usually minutes and if the exposure is to organic cyanogenetic substances can take hours because they must be metabolized. It has a smell of almonds, it does not occur as long as it is present, it is not detectable in $40 \%$ of cases (Razanamhandry et al., 2016).

The cutaneous manifestations are variable: a cherry red color of the skin is traditionally described due to the increase in the saturation of $\mathrm{Hb}$ (Hemoglobin) with $\mathrm{O}_{2}$ in venous blood due to the decrease in the use of $\mathrm{O}_{2}$ in the tissues. Blood in arteries and veins is the same color. Cyanosis has also, been described. If there is recovery of the acute picture, there are sequelae such as personality changes, memory deficits and extrapyramidal syndromes. It is described for chronic exposure: dermatitis, hypokinesia, mental deterioration, thyroid disease, visual disorders, optic atrophy (Gordo, 2018).

Physical-chemical properties of cyanide compounds: Table 1 shows the most important physicochemical properties of cyanide compounds.

Mechanism of toxicological action: Cyanide has great affinity for $\mathrm{Fe}$ as Ferric ion (++ ). After being absorbed, it reacts rapidly with the trivalent $\mathrm{Fe}$ of mitochondrial Cytochrome P 450 and in this way inhibits cellular respiration. Thus, cyanide efficiently blocks the production of ATP (Adenosine Triphosphate) and among 
other metabolic abnormalities, lactic acidosis and the decrease in the use of $\mathrm{O}_{2}$ by the cell that is cytotoxic hypoxia, can occur. The clinical and histopathological manifestations of the CNS are due to the inhibition in the use of $\mathrm{O}_{2}$ (Quintero et al., 2017).

The exact mechanism is not defined but it would be due to the inhibition of antioxidant enzymes such as catalases, glutathione dehydrogenase, glutathione reductase or superoxide dismutase. The interaction of cyanide with cytochrome oxidase is reversible through endogenous detoxification pathways including sulfurotransferases. These routes are the research bases for effective antidotes. Among the sulfurotransferases is the kinase which is a mitochondrial enzyme that transforms cyanide into thiocyanate by binding it to a sulfide group. The thiocyanate thus formed has little toxicity. This reaction can be hastened by the administration of sodium thiosulfate that adds sulfur molecules (Agudelo et al., 2010).

Generalities of the cyanate: The Cyanate (CON-) has an interest in the analysis of industrial wastewater due to the alkaline chlorination process used to oxidize cyanide which produces cyanate in the second reaction. The cyanate is unstable at neutral or low $\mathrm{pH}$, therefore, the sample should be stabilized as soon as it is obtained by the addition of sodium hydroxide until $\mathrm{pH}>12$, the cyanate around 7 can continue to be oxidized with chlorine to produce $\mathrm{CO}_{2}$ and $\mathrm{N}_{2}$ in addition, it can be hydrolyzed in ammonia when heated to a low $\mathrm{pH}$ (Quispe et al., 2011).

\section{RESULTS AND DISCUSSION}

Conventional treatments: Remediation of cyanide: there are several procedures for the treatment of cyanides and they include several physical methods, adsorption, complexation and oxidation. These methods predominantly include separation or destruction processes and can occur naturally. The separation processes that include physical methods, adsorption and complexation are used to concentrate and thus recover the cyanide by recycling. On the other hand, destruction processes are used to vary the carbon-nitrogen triple bond and thus destroy cyanide and produce non-toxic or less toxic species that are commonly required as oxidation methods (Garica, 2015).

Within oxidation processes, the most recent applications are photocatalytic methods. Photolysis can increase the redox reaction by supplying electromagnetic radiation energy to catalyze electron transfer processes. Electromagnetic radiation is absorbed, causing in an electron of the absorbent compound the passage from an internal state to an excited state, possibly separating pairs of electrons from one to another. Electrons are more susceptible and therefore more apt to participate in redox reactions (Fajardo et al., 2010).

Photoreduction occurs when the absorbing species donates the electron to other species. Photooxidation occurs when the absorbing species accepts an electron of another species in order to fill these vacant electrons. Excited electrons eventually relax to internal states of the reaction products. The energy needed to promote electrons from a basal state to the excited state is usually equivalent to that possessed by Ultraviolet (UV) radiation (Quiroga and Olmos, 2009).

Many redox reactions can be catalyzed by exposure to artificial currents such as arc, lamp and laser or by sunlight. High sources of energy such as gamma radiation and low as visible light can be used but are limited. Photolytic reactions can be induced directly if the absorbent compound is the species that is remediated or indirectly if the absorbent compound is available to transfer photo energy to the remediated species (Sancho et al., 2011).

Photolysis can be carried out in the absence of photosensitizers (direct photolysis) or in the presence of aqueous species (homogeneous photolysis and photocatalysis) or solid semiconductors (heterogeneous photocatalysis). These photochemical methods are relatively new technologies and are known as advanced oxidation processes. Homogeneous photocatalysis is rarely practiced due to the difficulty in the separation of aqueous species by recycling. Heterogeneous photocatalysis is more viable because solid-liquid separation processes are standard and can use a fixed-bed system (Garces Giraldo et al., 2004).

Advanced oxidation processes for the elimination of pollutants: contaminated water can generally be processed by biological treatment plants by absorption with activated carbon or other adsorbents or by conventional chemical treatments (thermal oxidation, chlorination, ozonation, potassium permanganate, etc.). However in some cases these procedures are inadequate to achieve the degree of purity required by law or for the subsequent use of the treated effluent which has led to the development of new wastewater purification technologies (Domenech et al., 2001; Alrousan et al., 2012).

These new technologies are within Advanced Oxidation Processes or Advanced Oxidation Technologies (PAOs or TAOs) that are based on physicochemical processes capable of producing profound changes in the chemical structure of pollutants. 
The concept was initially established by Glaze and his collaborators (Carey et al., 1976) who defined the PAOs as processes that involve the generation and use of powerful transient species, mainly the Hydroxyl radical $\left(\mathrm{OH}^{\circ}\right)$. This radical can be generated by photochemical means (including sunlight) or non-photochemical and have high effectiveness for the oxidation of organic matter (Domenech et al., 2001).

Classification of advanced oxidation technologies: No Photochemistry; these originate powerful reactive species, mainly the hydroxyl radical, through the transformation of chemical species or through the use of different forms of energy with the exception of light radiation. Within these technologies are (Domenech et al., 2001; Kopytko et al., 2017)

- Ozonation in an alkaline medium

- Ozonization in hydrogen peroxide

- The Fenton $\left(\mathrm{Fe}_{2}+/ \mathrm{H}_{2} \mathrm{O}_{2}\right)$ and related processes

- Electrochemical oxidation

Photochemicals: These processes are important for compounds that react slowly with the hydroxyl radical. Avoid the use of $\mathrm{O}_{3}$ or reduce its proportion with the consequent reduction of costs, health risks and environmental concerns. Within these technologies are (Domenech et al., 2001; Lopez and Sierra, 2012):

- Photolysis of water in the vacuum ultraviolet

- UV/ozone

- The heterogeneous photocatalysis

Advantages of advanced oxidation technologies: Some advantages are (Domenech et al., 2001; Duran et al., 2009). Not only do they change the phase to the pollutant (as in the case of air entrainment or activated carbon treatment) but they also chemically transform it. Complete mineralization (destruction) of the contaminant is generally achieved. On the other hand, conventional technologies that do not use highly oxidizing species do not completely oxidise organic matter. They are very useful for refractory contaminants that resist other treatment methods, mainly biological. They serve to treat pollutants at a very low concentration (for example, ppb). They are ideal to reduce the concentration of compounds formed by alternative pretreatments such as disinfection. They consume much less energy than other methods (for example incineration).

Heterogeneous photocatalysis: The process of solar detoxification by photocatalysis consists of the use of the most energetic part of the solar spectrum (wavelength less than $400 \mathrm{~nm}$ (nanometers)) to cause an oxidation reaction.

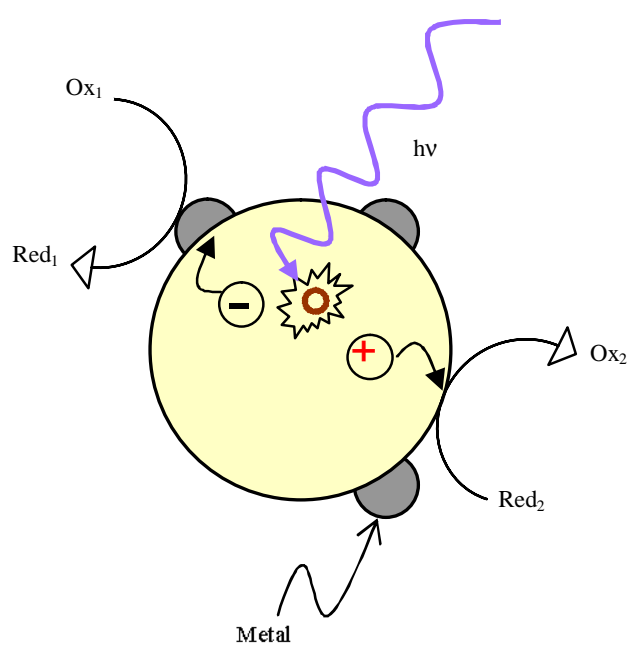

Fig. 1: Schematic representation of the reaction of electron transfer to the semiconductor

Particle $\left(\mathrm{TiO}_{2}\right)$

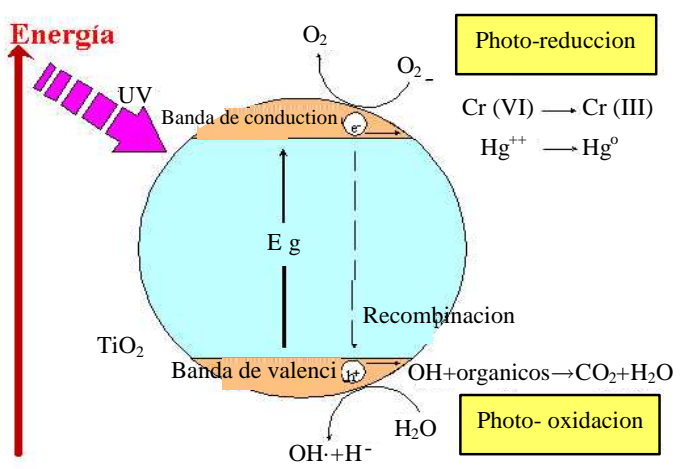

Fig. 2: Schematic representation of electron-hole pair formation in a semiconductor particle

This occurs when ultraviolet radiation activates a semiconductor such as Titanium dioxide $\left(\mathrm{TiO}_{2}\right)(\mathrm{Mesa}$, 1998). The process is heterogeneous because there are two active phases, solid and liquid (Cardona, 2001, Laliberte, 2015).

When the titanium dioxide is irradiated with light, the electrons (e-) are excited from the valence band to the conduction band, generating electronic voids in the valence band called hollows ( $\mathrm{hb}+$ ) (Eq. 1 and Fig. 1 and 2). The two carriers $(\mathrm{e}-\mathrm{h}+$ ) can recombine (Eq. 2 ) and be placed quickly on the surface of the oxide where they are trapped in intrinsic subsurface energy traps ( $\mathrm{Ti}$ IV- $\mathrm{O}_{2}-\mathrm{Ti}$ IV) for the holes and surface traps (-TiIV-) for the electrons (Eq. 3 and 4). The carriers (e- and $\mathrm{h}+$ ) being on the surface of the oxide can perform interfacial electron transfers with Donors (D) such as $\mathrm{OH}-, \mathrm{H}_{2} \mathrm{O}$ and 
Acceptors (A) such as oxygen, adsorbed on the surface of titanium dioxide, carrying out redox reactions (Eq. 5 and 6). The low quantum yield of photocatalytic reactions is due to the speed of recombination. Recombination is not carried out or is carried out in small quantity when the carriers interact rapidly with the donors and acceptors but it is essential that the donors and acceptors are preabsorbed before the luminous excitation of the $\mathrm{TiO}_{2}$. Because titanium dioxide lacks continuous interband states (those that facilitate recombination), the carriers (e- and $\mathrm{h}+$ ) have sufficiently long half-life times to allow them to perform the interfacial transfer of electrons (Mesa, 1998; Serpone, 1997; Osathaphan et al., 2008).

$$
\begin{gathered}
\mathrm{TiO}_{2}+\mathrm{hv}_{<387.5} \rightarrow\left(\mathrm{e}^{-}, \mathrm{h}^{+}\right) \\
\mathrm{e}^{-}+\mathrm{h}^{+} \rightarrow \mathrm{TiO}_{2}+\text { calor } \mathrm{y} / \mathrm{o} \text { ho } \\
\left(\mathrm{Ti}^{\mathrm{IV}}-\mathrm{O}^{2-}-\mathrm{Ti}^{\mathrm{IV}}\right)_{\text {subusp. }}+\mathrm{h}^{+} \rightarrow\left(\mathrm{Ti}^{\mathrm{IV}}-\mathrm{O}^{-} \mathrm{Ti}^{\mathrm{IV}}\right)_{\text {sub sup. }} . \\
\left(-\mathrm{Ti}^{\mathrm{IV}}-\right)_{\text {sup. }}+\mathrm{e}^{-} \rightarrow\left(-\mathrm{Ti}^{\mathrm{III}}-\right)_{\text {sup. }} \\
\mathrm{h}^{+}+\mathrm{D} \rightarrow \mathrm{D}^{+} \\
\mathrm{e}^{-}+\mathrm{A} \rightarrow \mathrm{A}^{-}
\end{gathered}
$$

The speed and efficiency of photocatalysis are significantly improved in the presence of molecular oxygen or inorganic oxidizing species such as peroxydisulfate, periodate and peroxides. Molecular oxygen decreases the recombination between the two carriers (e- and $\mathrm{h}+$ ) because when it is adsorbed on the surface of the semiconductor it is phototransformed to the peroxide anion $\mathrm{O}_{2}$, , remaining adsorbed. Peroxide $\mathrm{O}_{2}$ - is an effective oxidizing agent that can attack adsorbed and non-adsorbed organic compounds or can be reduced with the electrons generated in the irradiation of $\mathrm{TiO}_{2}$ by forming the divalent anion peroxide, $\mathrm{O}_{2}$. In this way the $\mathrm{h}+$ do not run the risk of recombining with the electrons and on the contrary they participate in the generation of the hydroxyl free radical (Mesa, 1998; Gomez et al., 2000; Parmon et al., 2002; Feng et al., 2018).

Parameters that influence the process: Many parameters influence qualitatively and quantitatively in the photocatalytic oxidation-reduction process and as a consequence, are decisive in the overall efficiency of the process. The most important are (Gomez et al., 2000; Mekuto et al., 2016; Yu et al., 2016).
pH: Normally, the photocatalysis process is more efficient in an acid medium $(3 \leq \mathrm{pH} \leq 5)$. The $\mathrm{pH}$ affects the surface properties of the catalyst and the chemical form of the compound to be degraded and this manifests itself in alterations in the rate of degradation and in the tendency to flocculate the catalyst. In the case of cyanides, it is important to maintain the basic $\mathrm{pH}$ because the formation of hydrocyanic acid occurs in acid.

Catalyst: In heterogeneous photocatalysis, multiple semiconductors have been used, such as $\mathrm{Al}_{2} \mathrm{O}_{3}, \mathrm{ZnO}$, $\mathrm{Fe}_{2} \mathrm{O}_{3}$ and $\mathrm{TiO}_{2}$ However, the most widely used is titanium dioxide because it has a greater photocatalytic activity, it is not toxic, it is stable in aqueous solutions and it is not very expensive. The anatase crystalline form of $\mathrm{TiO}_{2}$ seems to be the crystalline form with better photocatalytic properties and this has been attributed, among other reasons, to the greater capacity of photoadsorption of anatase by molecular oxygen and its ionized forms and its low relative speed of pair recombination hollow-electron. The optimal concentration of catalyst that provides a total adsorption of the efficient photons for the $\mathrm{TiO}_{2}$ Degussa P-25 varies from $0.1-5.0 \mathrm{~g} / \mathrm{L}$ (Gimenez et al., 1999; Percherancier et al., 1995; Fortuna et al., 2015).

In order to increase its photocatalytic efficiency, $\mathrm{TiO}_{2}$ has been subjected to doping with various metal ions (Pozzo et al., 1997; Cardona, 2001; Liu et al., 2013) it has also been tried to sensitize the catalyst to wavelengths. greater, (visible light) using dyes or colorants, both organic and organometallic. So, far, positive results have not been obtained. The titanium dioxide produced by Degussa under the trade name of P25 is the unsupported catalyst most used for having shown greater effectiveness. It is a semiconductor that exists in three crystalline forms: anatase, rutile and brokite; the most common forms are anatase and rutile since they are the most effective in the treatment of wastewater, the band gap energy for the anatase form is approximately $3.2 \mathrm{eV}$ and for the rutile phase $3.0 \mathrm{eV}$. The $\mathrm{TiO}_{2}$ Degussa P-25 is produced by flame hydrolysis of titanium tetrachloride at high temperatures (greater than $12000 \mathrm{C}$ ) in the presence of hydrogen and oxygen. The powder $\mathrm{TiO}_{2} \mathrm{P}-25$ has a surface area of $50 \pm 15 \mathrm{~m}^{2} / \mathrm{g}$ and an average particle diameter of $21 \mathrm{~nm}$. The product is cubic particles with rounded edges, non-porous and has a $99.5 \%$ purity (anatase ratio: rutile 70:30).

Primary studies of photocatalytic degradation of cyanide: The first publication on the process of degradation by heterogeneous photocatalysis of pollutants in both aqueous and gaseous phases is due to Carey et al. (1976), 
Since then, a historical analysis of the evolution of the development of the photocatalytic process for water purification allows the identification of four clearly different stages. In the first stage with scarce publications, roughly between 1976 and 1985, only a few scientific groups worked on the subject-no specific application was yet visible. The second stage, from the mid-1980 s to the first years of the $1990 \mathrm{~s}$, coincided with a growing concern and concern of the international scientific community on environmental issues. In it, the possibility of applying this process to the treatment of pollutants in water was raised (Al-Ekabi and Serpone 1988, Arias-Lafargue et al., 2017).

The success of the first experiences gave rise to a massive incorporation at the end of the 80 s and as results of very optimistic extrapolations of the results obtained until then, came to be considered the photocatalytic process as a possible universal method for the degradation of organic pollutants (Mesa, 1998; Kim et al., 2018).

In the first stage that can be framed between the mid and late 90 's there was a proliferation of contradictory results which is why the basic research studies and their applications generated a debate about the real possibilities of application of the process. Emphasis was placed on the drawbacks of the limitations to produce large quantities of hydroxyl radicals and the slowness of the global degradation process. Encouraging results were obtained when studying almost real systems, simultaneously with other negative or doubtful results, generating much confusion in the perception of the non-scientific public (Mesa, 1998; Donato et al., 2007, Baeissa, 2015).

The fourth stage in which we are currently is characterized by a more conservative and realistic view of the possibilities of associated technology, focused on those specific and specific applications in which technology, properly developed can be viable and competitive (Johnson, 2015).

Within the investigations, Peral et al. (1990) studied the oxidation of cyanide catalyzed by $\mathrm{TiO}_{2}$ under UV illumination. The research was carried out by determining the production of photo-oxidized cyanide using different concentrations, irradiation time, light intensity, $\mathrm{pH}$ and temperature values. They observed that during the first minutes of irradiation the main product of the oxidation was OCN-but in long times all the cyanide was converted to $\mathrm{CO}_{3-2}$. From the kinetic analyzes carried out, it was deduced that the oxidation constant of the cyanide by photo generated holes is $70 \%$ of the corresponding water oxidation constant.

Hidaka et al. (1992) studied heterogeneous photocatalytic degradation of cyanide on $\mathrm{TiO}_{2}$ surface.
They built a large-scale photoreactor that was an excellent resource for the decomposition of large amounts of cyanide and quantitatively determined the disappearance of $\mathrm{CN}$-, the consumption of $\mathrm{O}_{2}$, the intermediate formation of $\mathrm{OCN}$ - and the mineralization last to $\mathrm{CO}_{2}$ and $\mathrm{N}_{2}$.

Bravo et al. investigated the photocatalytic oxidation of cyanide to nitrate with $\mathrm{TiO}_{2}$. They established that the photocatalytic oxidation of cyanate ions in aqueous solution and in the presence of $\mathrm{TiO}_{2}$ takes place by two different reaction routes, depending on the $\mathrm{pH}$ of the solution. For $\mathrm{pH}$ lower than 10 , the main product of oxidation is nitrate instead of $\mathrm{N}_{2}, \mathrm{NH}_{4}+$ is formed by hydrolysis of OCN- and this photo-oxidation produces nitrate and nitrite; the proportion of the hydrolysis controls the reaction speed of the whole process. The photo-oxidation of $\mathrm{OCN}$ - to $\mathrm{N}_{2}$ occurs in a strongly basic medium. For $\mathrm{pH}$ values lower than $5, \mathrm{NH}_{4}+$ is difficult to oxidize, remaining stable in solution.

Choi et al. (1994) analyzed the effect of doping nanoparticles of $\mathrm{TiO}_{2}$ with 21 metals, improving in some cases the oxidative capacity and in others the reductive capacity of $\mathrm{TiO}_{2}$, due to the nature, concentration and distribution of the dopant.

Ahmed and Attia (1995) studied airgel materials by detoxifying cyanide in wastewater. They used ultraviolet radiation and $\left(\mathrm{TiO}_{2}-\mathrm{SiO}_{2}\right)$ airgel as a photocatalyst to oxidize and degrade aqueous cyanide species to $\mathrm{CO}_{2}$ and $\mathrm{N}_{2}$; prepared the photocatalyst airgel by sol-gel technique and supercritical drying with different contents of $\mathrm{SiO} 2$ $\left(\mathrm{TiO}_{2} \mathrm{SiO}_{2}\right.$, molar ratio 1:1.3,1:2.6 and 1:3.9) and observed that by increasing the $\mathrm{SiO}_{2}$ content it apparently decreases the density and translucency increases. They compared the high photocatalytic activity by oxidation of $\mathrm{CN}$ - in diluted solutions (1000 and $522 \mathrm{ppm}$ ) of ferric cyanide with titanium powder and proved that the airgel with a high content of $\mathrm{SiO}_{2}\left(\mathrm{TiO}_{2}: \mathrm{SiO}_{2}\right.$ molar ratio 1:3.9) had high efficiency in photocatalytic oxidation of $\mathrm{CN}$-species under experimental conditions.

Augugliaro et al. (1997) investigated the photocatalytic oxidation of cyanides in aqueous suspension of $\mathrm{TiO}_{2}$ irradiated in the UV-Near region. They studied the proportion of photo-oxidized cyanide by variation of parameters: initial concentration of cyanide, Catalyst concentration initial $\mathrm{pH}$, power of radiation and concentration of chloride ions in the reaction mixture. They observed that the photo-oxidation of cyanide is affected by the concentration of the catalyst, the concentration of the chloride ions and the power of irradiation which was independent of the initial concentration of the cyanide and the $\mathrm{pH}$; they used the kinetic model of Langmuir-Hinshelwood. They also, investigated the reaction path where cyanide, nitrate and carbonate were the main products. 
Chiang et al. (2002) investigated the photocatalytic degradation of cyanide using $\mathrm{TiO}_{2}$ modified with copper oxide. The copper content on the $\mathrm{TiO}_{2}$ surface was varied from $0.05-10.0 \%$ and found that the $\mathrm{CuO}$ deposits in nanoparticles were present on the $\mathrm{TiO}_{2}$ surface. They also, found that the photo-oxidation path of the cyanide with the doped catalyst was slightly improved at $0.1 \% \mathrm{Cu}$, also, decreasing the photocatalytic degradation of the $\mathrm{CN}$-, explained in terms of the ion competition reaction of $\mathrm{Cu}$ cyanide complexes. By the superficial hydroxyl radicals and as a final product the cyanide was oxidized to cyanate.

Hernandez-Alonso et al. (2002) studied the increased activity by ozone of aqueous suspensions of titanium dioxide for the photocatalytic oxidation of $\mathrm{CN}$-free. They used a batch-type photoreactor with immersed lamp to treat aqueous and irradiated suspensions in the near UV region, using air or ozone-air mixtures as oxidation reagents, producing measurable speeds up to low cyanide concentration values. In the presence of ozone, the rate of oxidation of cyanide by the heterogeneous photocatalytic mechanism is increased for their results they took into account the Langmuir-Hinshelwood equations and reached that ozone strongly interacts with $\mathrm{TiO}_{2}$ leading mainly to the formation of ozonide radicals.

Amal et al. found the kinetics and mechanisms of photocatalytic oxidation of cyanide in the presence of the $\mathrm{TiO}_{2}$ catalyst. Where the quantum efficiency of oxidation was low (0.1-0.2\%) due to 11-Low absorption of cyanide ions on the surface of $\mathrm{TiO}_{2}$. Absence of homogenous reaction between cyanide ions and diffused hydroxyl radicals. High recombination speed of hollow electron in the photocatalyst $\mathrm{TiO}_{2}$. They developed a kinetic model to describe the mechanism involved in the photocatalytic oxidation of cyanide and concluded that the only oxidation product detected was cyanate type and they followed the direct oxidation of cyanate by photo generated holes.

Davit et al. (2003) investigated the photocatalytic absorption and degradation of acetonitrile with FT-IR (Infrared spectrometers with Fourier Transform). In the degradation they used a Batch type reactor with 2 types of commercial $\mathrm{TiO}_{2}$ powder (Merck and Degussa P-25) as photocatalyst and obtained the initial conversion rate of the highest acetonitrile with $\mathrm{Merck} \mathrm{TiO}_{2}$ than with $\mathrm{TiO}_{2}$ Degussa P-25. They used the (FT-IR) to investigate the molecular aspects of the absorption and photo-oxidation of acetonitrile on the two powders of $\mathrm{TiO}_{2}$ whose surfaces were completely hydrated. They found that the absorption of acetonitrile is reversible only for the Merck $\mathrm{TiO}_{2}$ and the stable photo acetamido species formed on $\mathrm{TiO}_{2}$ could poison some photocatalytic sites evidenced by the initial conversion rate loss of acetonitrile.
Oh and Jenks (2004) studied the photocatalytic degradation of a cyanuric acid in $\mathrm{R}$ recalcitrant species. This degradation occurred in aqueous suspensions with $\mathrm{TiO}_{2}$ (Degussa P25) by addition of the fluoride ion at low $\mathrm{pH}$, subjecting itself to the formation of hydroxyl radicals in homogeneous phase, for this hypothesis took into account the degradations of 4-t-butylpyrazine and other compounds organics provided with $\mathrm{TiO}_{2}$.

Photocatalytic degradation of cyanides: The photocatalytic degradation of cyanides is another interesting application, since, this technique does not produce sludge or highly toxic compounds, such as cyanogen chloride, it avoids the use of products difficult to handle such as chlorine and does not It is necessary to store chemical reagents. Another additional advantage is the possible recovery of the metal normally complexed to cyanide. Photocatalytic oxidation is capable of transforming $\mathrm{CN}$ - into products such as cyanate, OCN(about 1000 times less toxic) with a careful choice of reaction conditions. Once this conversion is achieved, the OCN- is completely oxidized and the final products are mainly $\mathrm{CO}_{2}$ and $\mathrm{NO}_{3}$ (Mesa, 1998; Bruger et al., 2018).

$$
\begin{gathered}
\mathrm{CN}^{-}+2 \mathrm{OH}^{-}+2 \mathrm{~h}_{\mathrm{BV}}^{-} \rightarrow \mathrm{OCN}^{-}+\mathrm{H}_{2} \mathrm{O} \\
\mathrm{OCN}^{-}+4 \mathrm{O}_{2}+4 \mathrm{H}_{2} \mathrm{O} \rightarrow \mathrm{NO}_{3}^{-}+\mathrm{CO}_{2}+\mathrm{H}_{2} \mathrm{O}_{2}
\end{gathered}
$$

Mechanism for oxidation of cyanide: The heterogeneous photocatalysis has been used for oxidation of cyanide and three mechanisms are proposed. The first mechanism produces hydroxyl radicals via reduction of adsorbed water or hydroxide adsorbed by gaps in the valence band:

$$
\mathrm{H}_{2} \mathrm{O}+\mathrm{h}+\mathrm{OH}^{*}+\mathrm{H}+
$$

$$
\mathrm{OH}-+\mathrm{h}+\mathrm{OH}^{*}
$$

On the other hand, hydroxyl radicals are produced by the second mechanism by reaction of dissolved oxygen with excited electrons and in the conduction band through an intermediate superoxide $\left(\mathrm{O}^{-2}\right)$ :

$$
\begin{gathered}
\mathrm{O}_{2}(\mathrm{aq})+\mathrm{e}^{-} \rightarrow \mathrm{O}_{2}^{-} \\
2 \mathrm{O}_{2}^{-}+2 \mathrm{H}^{+} \rightarrow 2 \mathrm{OH}^{*}+\mathrm{O}_{2}(\mathrm{aq})
\end{gathered}
$$

The two reaction mechanisms show that the final products are cyanide oxidized to cyanate, nitrogen gas, 
nitrite and nitrate by the hydroxyl radicals and are also, effective for the remediation of thiocyanate, (INADs) and SADs. The third mechanism involves the reduction of cyanide by voids in the valence band to produce Cianil $\mathrm{CN}^{*}$ radicals:

$$
\mathrm{CN}^{-}+\mathrm{h}^{+} \rightarrow \mathrm{CN}^{*}
$$

Hydroxyl radicals produced according to the above reactions that react with the Cyanyl radicals:

$$
\mathrm{CN}^{*}+\mathrm{OH}^{*} \rightarrow \mathrm{OCN}^{-}+\mathrm{H}^{+}
$$

Resulting cyanate that additionally reacts with hydroxyl radicals (Barakat et al., 2004).

\section{CONCLUSION}

The review of the literature shows that in the reaction systems it is allowed to show a high percentage of degradation of cyanide in aqueous medium which indicates the use of photocatalytic technology in the treatment of persistent compounds, such as cyanide using $\mathrm{TiO}_{2}$ and $\mathrm{TiO}_{2}$. Doped with copper heteropolyolyb date as a catalyst. It is also, well known that the factors that most influence the photocatalytic degradation are: type of catalyst, reaction time initial concentration of cyanide, catalyst concentration and air flow. Likewise, the degradation system shows that the total cyanides, present in the aqueous residual discharges, coming from the mining sector, can be degraded by means of the heterogeneous photocatalysis, providing a viable alternative for the destruction of contaminants that are in effluents watery. Finally, the photocatalytic degradation when air is supplied is higher than that obtained when it is absent, therefore, the supply of oxygen is important because it increases the rate of degradation of the substrate, since when it is not supplied, it tends to exhaust the oxygen that is dissolved in water.

\section{REFERENCES}

Acheampong, M.A. and P.N. Lens, 2014. Treatment of gold mining effluent in pilot fixed bed sorption system. Hydrometallurgy, 141: 1-7.

Aguldelo, R., J. Betancur and C. Jaramillo, 2010. [Biotreatment of cyanide waste and its relation to public health (In Spanish)]. Rev. Fac. Nac. Salud Publica, 28: 7-20.

Ahmed, M.S. and Y.A. Attia, 1995. Aerogel materials for photocatalytic detoxification of cyanide wastes in water. J. Non Cryst. Solids, 186: 402-407.
Al-Ekabi, H. and N. Serpone, 1988. Kinetics studies in heterogeneous photocatalysis,I photocatalytic degradation of chlorinated phenols in aerated aqueous solutions over $\mathrm{TiO}_{2}$ supported on a glass matrix. J. Phys. Chem., 92: 5726-5731.

Alrousan, D.M.A., M.I. Polo-Lopez, P.S.M. Dunlop, P. Fernandez-Ibanez and J.A. Byrne, 2012. Solar photocatalytic disinfection of water with immobilised titanium dioxide in re-circulating flow $\mathrm{CPC}$ reactors. Applied Catal. B: Environ., 128: 126-134.

Anonymous, 1984. [Decree 1594 of 1984. through which the uses of water and liquid waste are regulated]. Ministry of Health and Social Protection, Bogota, Colombia. (In Spanish)

Arias-Lafargue, T., D. Fernandez-Compta, Y. SanchezRodriguez and A. Lasserra-Portuondo, 2017. [Influence of leaching on the recovery of gold at the Oro-Barita mine in Santiago de Cuba (In Spanish)]. Chem. Technol., 37: 461-476.

Augugliaro, V., V. Loddo, G. Marci, L. Palmisano and M.J. Lopez-Munoz, 1997. Photocatalytic oxidation of cyanides in aqueous titanium dioxide suspensions. J. Catal., 166: 272-283.Augugliaro, V., V. Loddo, G. Marci, L. Palmisano and M.J. Lopez-Munoz, 1997. Photocatalytic oxidation of cyanides in aqueous titanium dioxide suspensions. J. Catal., 166: 272-283.

Baeissa, E.S., 2015. Synthesis and characterization of sulfur-titanium dioxide nanocomposites for photocatalytic oxidation of cyanide using visible light irradiation. Chin. J. Catal., 36: 698-704.

Barakat, M.A., Y.T. Chen and C.P. Huang, 2004. Removal of toxic cyanide and $\mathrm{Cu}$ (II) ions from water by illuminated $\mathrm{TiO}_{2}$ catalyst. J. Applied Catalysis B: Environ., 53: 13-20.

Barrios, R.L.A., C.A.S. Sierra and J.D.C.J. Morales, 2017. [Toxic effects of paracetamol on human health and the environment (In Spanish)]. Agrar. Res. Magaz., 8: 139-149.

Bruger, A., G. Fafilek and L. Rojas-Mendoza, 2018. On the volatilisation and decomposition of cyanide contaminations from gold mining. Sci. Total Environ., 627: 1167-1173.

Cardona, S.P.P., 2001. Coupling of photocatalytic and biological processes as a contribution to the detoxification of water. Ph.D Thesis, Ecole Polytechnique Federale de Lausanne, Lausanne, Switzerland.

Carey, J.H., J. Lawrence and Y.H.M. Tosine, 1976. Photodechlorination of PCBs in the presence of titanium dioxide in aqueous suspensions. Bull. Environ. Contam. Toxicol., 16: 697-701. 
Chiang, K., R. Amal and T. Tran, 2002. Photocatalytic degradation of cyanide using titanium dioxide modified with copper oxide. Adv. Environ. Res., 6: 471-485.

Chiang, K., R. Amal and T. Tran, 2003. Photocatalytic oxidation of cyanide: Kinetic and mechanistic studies. J. Mol. Catal. Chem., 193: 285-297.

Choi, W.Y., A. Termin and M.R. Hoffmann, 1994. Romote bleaching of methylene blue by UV irradiated $\mathrm{TiO}_{2}$ in the gas phase. J. Phys. Chem., 98: 13669-13679.

Dash, R.R., A. Gaur and C. Balomajumder, 2009a. Cyanide in industrial wastewaters and its removal: A review on biotreatment. J. Hazardous Mater., 163: 1-11.

Dash, R.R., C. Balomajumder and A. Kumar, $2009 \mathrm{~b}$. Removal of cyanide from water and wastewater using granular activated carbon. Chem. Eng. J., 146: 408-413.

Davit, P., G. Martra, S. Coluccia, V. Augugliaro and E.G. Lopez et al., 2003. Adsorption and photocatalytic degradation of acetonitrile: FT-IR investigation. J. Mol. Catal. Chem., 204: 693-701.

Domenech, X., W.F. Jardim and M.I. Litter, 2001. [Advanced Oxidation Processes for the Elimination of Pollutants]. In: [Elimination of Contaminants by Heterogeneous Photocatalysis], CYTED. (Ed.). National Atomic Energy Commission, Buenos Aires, Argentina, pp: 3-25 (In Spanish).

Donato, D.B., O. Nichols, H. Possingham, M. Moore and P.F. Ricci et al., 2007. A critical review of the effects of gold cyanide-bearing tailings solutions on wildlife. Environ. Intl., 33: 974-984.

Duran, A., J.M. Monteagudo, I. San Martin and R. Sanchez-Romero, 2009. Photocatalytic treatment of IGCC power station effluents in a UV-pilot plant. J. Hazard. Mater., 167: 885-891.

Dwivedi, N., C. Balomajumder and P. Mondal, 2016. Comparative investigation on the removal of cyanide from aqueous solution using two different bioadsorbents. Water Resour. Ind., 15: 28-40.

Fajardo, J.A., D.C. Burbano, E.J. Burbano, N.J. Apraez and M.I.L.T.O.N. Rosero Moreano, 2010. [Study of chemical methods of cyanide removal present in cyanide residues from the vein gold extraction process in the Department of Narino (In Spanish)]. Revista Luna Azul, 31: 8-16.

Feng, C., C. Aldrich, J.J. Eksteen and D.W.M. Arrigan, 2018. Removal of arsenic from gold cyanidation process waters by use of cerium-based magnetic adsorbents. Miner. Eng., 122: 84-90.

Fortuna, D., A. Rahimsyah and Y. Puspitasri, 2015. Degradation of acid cyanide poison in rubber seed (Hevea brasiliensis) after treatment with rice husk ash. Intl. J. Adv. Sci. Eng. Inf. Technol., 5: 291-293.
Garces Giraldo, L.F., M. Franco, E. Alejandro and J.J. Santamaria Arango, 2004. [Photocatalysis as an alternative for wastewater treatment (In Spanish)]. Lasallista Magaz. Invest., 1: 83-92.

Garcia, D.E.G., 2015. [Assessment of ecological impacts due to gold mining in the Guabas River, Valle del Cauca, Colombia (In Spanish)]. Magaz. Agrar. Environ. Res., 6: 243-254.

Garcia-Ochoa, F. and A. Santos, 2001. [Catalytic Oxidation of Phenolic Compounds in Wastewater]. In: Catalysts and Adsorbents for Environmental Protection in the Ibero-American Region, Jesus Blanco, P.A. (Ed.). Programa Iberoamericano de Ciencia y Tecnología para el Desarrollo, Madrid, Spain, pp: 275-284.

Gebresemati, M., N. Gabbiye and O. Sahu, 2017. Sorption of cyanide from aqueous medium by coffee husk: Response surface methodology. J. Applied Res. Technol., 15: 27-35.

Gimenez, J., D. Curco and M.A. Queral, 1999. Photocatalytic treatment of phenol and 2, 4dichlorophenol in a solar plant in the way to scaling-up. Catal. Today, 54: 229-243.

Gomez, L., A. Urkiaga, M. Gutierrez and L. De las Fuentes, 2000. [Photooxidation for chemical spills: Review and experiences of advanced oxidation processes (In Spanish)]. Chem. Eng. Magaz., 32: 211-216.

Gordo, D.A.M., 2018. [Phenolic compounds, an approach to your biosynthesis, synthesis and biological activity (In Spanish)]. Magaz. Agrar. Environ. Res., 9: 81-104.

Guadalima, M.P.G. and D.A.N. Monteros, 2018. Evaluation of the rotational speed and carbon source on the biological removal of free cyanide present on gold mine wastewater, using a rotating biological contactor. J. Water Proc. Eng., 23: 84-90.

Hernandez-Alonso, M.D., J.M. Coronado, A.J. Maira, J. Soria and V. Loddo et al., 2002. Ozone enhanced activity of aqueous titanium dioxide suspensions for photocatalytic oxidation of free cyanide ions. Appl. Catal. Environ., 39: 257-267.

Hidaka, H., T. Nakamura, A. Ishizaka, M. Tsuchiya and J. Zhao, 1992. Heterogeneous photocatalytic degradation of cyanide on $\mathrm{TiO}_{2}$ surfaces. J. Photochem. Photobiol. Chem., 66: 367-374.

Irfan, U.R., I. Nur and M. Kasim, 2017. Hydrothermal alteration mineralogy associated with gold mineralization in Buladu Area, Gorontalo, Northern Sulawesi, Indonesia. Intl. J. Adv. Sci. Eng. Inf. Technol., 7: 2244-2250.

Jaramillo, G., J.A. Pabon and E.G. Pavas, 2002. 
[Photodegradation of phenols in industrial wastewater (In Spanish)]. Chem. Eng., 386: 117-122.

Johnson, C.A., 2015. The fate of cyanide in leach wastes at gold mines: An environmental perspective. Appl. Geochem., 57: 194-205.

Kim, T.K., T. Kim, A. Jo, S. Park and K.H. Choi et al., 2018. Degradation mechanism of cyanide in water using a UV-LED $/ \mathrm{H}_{2} \mathrm{O}_{2} / \mathrm{Cu}^{2+}$ system. Chemosphere, 208: 441-449.

Kopytko, M., S.N.C. Torres and M.J.E. Gomez, 2017. [Stimulated biodegradation of soils contaminated with organochlorine pesticides (In Spanish)]. Agrar. Environ. Res. J., 8: 119-130.

Kuyucak, N. and A. Akcil, 2013. Cyanide and removal options from effluents in gold mining and metallurgical processes. Miner. Eng., 50: 13-29.

Laliberte, M., 2015. Reducing the toxicity of gold-mine effluent using biological reactors and precipitation. Miner. Metall. Proc., 32: 1-5.

Liu, W., W. Sun, A.G. Borthwick and J. Ni, 2013. Comparison on aggregation and sedimentation of titanium dioxide, titanate nanotubes and titanate nanotubes- $\mathrm{TiO}_{2}$ : Influence of $\mathrm{pH}$, ionic strength and natural organic matter. Colloids Surf. Physicochemical Eng. Aspec., 434: 319-328.

Lopez, A.L.B. and I.M.C. Sierra, 2012. [Comparative catalytic study of the $\mathrm{TiO}_{2}$ and $\mathrm{Nb}_{2} \mathrm{O}_{5}$ systems in the degradation of cyanide according to the type of oxidant (In Spanish)]. Eng. Sci., 8: 257-280.

Malato, A., J. Blanco, A. Vidal and C. Richter, 2002. Photocatalysis with solar energy at a pilot-plant scale: An overview. Applied Catalysis B: Environ., 37: 1-15.

Mekuto, L., S.K. Ntwampe and A. Akcil, 2016. An integrated biological approach for treatment of cyanidation wastewater. Sci. Total Environ., 571: 711-720.

Mesa, G.A.P., 1998. [Photolysis and photodegradation sensitized with $\mathrm{Fe}_{3+}$ and $\mathrm{TiO}_{2}$ of pesticides in natural waters (In Spanish)]. Ph.D Thesis, Universidad de Barcelona, Barcelona, Spain.

Moussavi, G., M. Pourakbar, E. Aghayani and M. Mahdavianpour, 2018. Investigating the aerated VUV/PS process simultaneously generating hydroxyl and sulfate radicals for the oxidation of cyanide in aqueous solution and industrial wastewater. Chem. Eng. J., 350: 673-680.

Oh, Y.C. and W.S. Jenks, 2004. Photocatalytic degradation of a cyanuric acid, a recalcitrant species. J. Photochem. Photobiol. Chem., 162: 323-328.

Olivero-Verbel, J., K. Caballero-Gallardo and J. Negrete-Marrugo, 2011. Relationship between localization of gold mining areas and hair mercury levels in people from Bolivar, north of Colombia. Biol. Trace Element Res., 144: 118-132.

Osathaphan, K., B. Chucherdwatanasak, P. Rachdawong and V.K. Sharma, 2008. Photocatalytic oxidation of cyanide in aqueous titanium dioxide suspensions: Effect of ethylenediaminetetraacetate. Solar Energy, 82: 1031-1036.

Pala, A., R.R. Politi, G. Kursun, M. Erol and F. Bakal et al., 2015. Photocatalytic degradation of cyanide in wastewater using new generated nanothin film photocatalyst. Surf. Coat. Technol., 271: 207-216.

Parmon, V., A.V. Emeline and N. Serpone, 2002. Glossary of terms in photocatalysis and radiocatalysis. Intl. J. Photoenergy, 4: 91-131.

Peral, J., J. Munoz and X. Domenech, 1990. Photosensitized CNoxidation over $\mathrm{TiO}_{2}$. J. Photochem. Photobiol. Chem., 55: 251-257.

Percherancier, J.P., R. Chapelon and B. Pouyet, 1995. Semiconductor-sensitized photodegradation of pesticides in water: The case of carbetamide. J. Photochem. Photobiol. Chem., 87: 261-266.

Pirmoradi, M., S. Hashemian and M.R. Shayesteh, 2017. Kinetics and thermodynamics of cyanide removal by $\mathrm{ZnO}$ @ NiO nanocrystals. Trans. Nonferrous Met. Soc. China, 27: 1394-1403.

Pozzo, R.L., M.A. Baltanas and A.E. Cassano, 1997. Supported titanium oxide as photocatalyst in water decontamination: State of the art. Catal. Today, 39: 219-231.

Quintero, E.C., A.G.G. Bayona, M.A.H. Lopez and M.L.P. Rojas, 2017. [Strategic management of the production of sterile waste from sustainable mining, using eco-efficient mining practices in Colombia (In Spanish)]. Agrar. Environ. Res. J., 8: 107-118.

Quiroga, P.N. and V. Olmos, 2009. [Review of the toxicokinetics and toxicity of hydrocyanic acid and cyanides (In Spanish)]. Acta Toxicol. Argent., 17: 20-32.

Quispe, L., M.D.C. Arteaga, E. Cardenas, C. Santelices and E. Palenque et al., 2011. [Elimination of cyanide by combined $\mathrm{UV} / \mathrm{H}_{2} \mathrm{O}_{2} / \mathrm{TiO}{ }_{2}$ system (In Spanish)]. Boliv. J. Chem., 28: 113-118.

Ray, A.K., 1999. Design, modelling and experimentation of a new large-scale photocatalytic reactor for water treatment. Chem. Eng. Sci., 54: 3113-3125.

Razanamahandry, L.C., H.A. Andrianisa, H. Karoui, K.M. Kouakou and H. Yacouba, 2016. Biodegradation 
of free cyanide by bacterial species isolated from cyanide-contaminated artisanal gold mining catchment area in Burkina Faso. Chemosphere, 157: 71-78.

Sancho, J.P., B. Fernandez, J. Ayala, M.P. Garcia and A. Lavandeira, 2011. [Application of potassium permanganate for the elimination of copper cyanides in wastewater from the leaching plant in a gold mine (II): Pilot plant tests (In Spanish)]. Revista Metalurgia, 47: 224-233.

Sarla, M., M. Pandit, D.K. Tyagi and J.C. Kapoor, 2004. Oxidation of cyanide in aqueous solution by chemical and photochemical process. J. Hazard. Mater., 116: $49-56$.
Serpone, N., 1997. Relative photonic efficiencies and quantum yields in heterogeneous photocatalysis. J. Adv. Oxid. Technol., 2: 203-216.

Vidal, A., A.I. Dyaz, A. El Hraiki, M. Romero and I. Muguruza et al., 1999. Solar photocatalysis for detoxification and disinfection of contaminated water: Pilot plant studies. Catal. Today, 54: 283-290.

Yeddou, A.R., S. Chergui, A. Chergui, F. Halet and A. Hamza et al., 2011. Removal of cyanide in aqueous solution by oxidation with hydrogen peroxide in presence of copper-impregnated activated carbon. Miner. Eng., 24: 788-793.

Yu, X., R. Xu, C. Wei and H. Wu, 2016. Removal of cyanide compounds from coking wastewater by ferrous sulfate: Improvement of biode gradability. J. Hazard. Mater., 302: 468-474. 